\title{
sciendo
}

\section{Coordinates of healthcare systems in Russia and Romania}

\author{
Vladimir BULATNIKOV \\ Transilvania University of Brasov, Brasov, Romania \\ vladimir.bulatnikov@unitbv.ro \\ Cristinel CONSTANTIN \\ Transilvania University of Brasov, Brasov, Romania \\ cristinel.constantin@unitbv.ro
}

\begin{abstract}
The paper discusses the key features of the state of the structure of healthcare in Russia and Romania, the administration of this scheme is assessed and the statistical array takes place over a long period. The health sector's sustainable status is perceived to be the main target concern of each state. The medical care degree is the country-wide coefficient of well-being. However, not only at the state level, but also at the regional level, the characteristic effect of socio-economic factors on population health metrics is especially pronounced. Without the introduction of modern approaches to management, it's more professionalization, that is, the building of a management organization that insists on the professionalism of leadership, the solution to the problems of healthcare growth is unlikely. One of the essential national tasks of establishing a plan for the socio-economic growth of Russian and Romanian healthcare and raising the standard and quality of life of the people is to strengthen the healthcare system. The provision and management of the quality of patient services can be considered one of the most significant concerns in the area of healthcare. Moreover, these issues are the most difficult to address, which is why, during a time of economic and social turmoil, their importance grows significantly.
\end{abstract}

Keywords: healthcare, healthcare indicators, healthcare efficiency, state regulation and medical services.

\section{Introduction}

In Russia and Romania, over the past 25 years, there have been significant changes in the healthcare system sector (Kirillov and Putintsev, 2012). This article reviews the main indicators in the healthcare system sector for different countries with focus on Russia and Romania called as coordinates. During discussions we spotted lots of transition effects, aftereffects and problems which are obvious thanks to collected information in tables and figures. The most important of which is the transition to compulsory healthcare insurance (Ianole et al., 2014). As well as, during the last 12 years there have been at least two crises. Moreover, over the past 6 years there have been lots of sanctions in front of different countries (Zyukin et al., 2017). All these developments were reflected in our article. As a result of mentioned developments this served as an incentive to activate market regulators in the work of medical organizations, which resulted in a "significant increase in their prospects for attracting additional sources of funding as a result of the provision of paid medical services" (Chernenko et al., 2018). This, in our opinion, means a transition to competitive relations and the liberalization of business activities in the public healthcare sector. In fact, for this reason, in order to develop the healthcare system at the present stage, the implementation of measures aimed at improving the effectiveness of their work is considered a mandatory element of the functioning of each medical organization. Medical organizations that have switched to using such a management tool have managed to "significantly improve the main performance indicators of their activities" (Tashbulatova and Tashbulatov, 2018). Thereby the

DOI: $10.2478 /$ picbe-2021-0019

(C) 2021 V. Bulatnikov, C. Constantin, published by Sciendo.

This work is licensed under the Creative Commons Attribution 4.0 License. 
coordinates and main trends of these healthcare systems are needed to conclude results and implement new strategies for two countries, Russia and Romania.

Considering the above-mentioned topics, the goal of this research is to identify the main indicators and trends in global healthcare systems as well as with focus on Russian and Romanian cases to identify future marketing directions bringing all the best from the world's experience. In order to reach the research goal, we proposed to find answers to the following research questions: Q1. What are the current coordinates on healthcare in the world?; Q2. What are the results of the comparison of Russia and Romania healthcare systems?; Q3. What are the coordinates of the healthcare system in Russia?; Q4. What are the coordinates of the healthcare system in Romania?; The outcome of this analysis may offer perspectives to direct future studies on the marketing of healthcare systems in Russia and Romania, adapting to government plans and policies, adapting to new developments in the healthcare sector and reducing the difficulty of modernization of the marketing of healthcare systems.

\section{Literature review}

The forms of organization of national healthcare systems are diverse. Each country forms and develops its own unique system, which differ in the methods of attracting financial resources aimed at providing medical care and preserving the health of citizens. The quality, quantity and structure of the resources allocated by the society, the result of their application in the field of health protection are determined by the influence of economic and social factors (Dixon-File and Tomsan, 2012; Dorgan et al., 2011; Orlov and Sokolova, 2010).

Russia is a member of the Group of Twenty "G20", which represents the countries with the largest economies. In 2014, as the global economy recovered from the effects of the 2008 global financial crisis, economic and political restrictive measures called sanctions were imposed in response to Russia's policy in Crimea and towards Ukraine. "More than five years have passed since the introduction of sanctions, and Russia has not changed its position on the world political arena", which indicates that the sanctions have not had a fundamental effective impact (Zyukin et al., 2017). However, their impact cannot but have a negative impact on economic processes, increasingly penetrating into all sectors of the Russian economy, exacerbating the internal structural problems of our country. The policy of sanctions also harms the world economy as a whole, since in the context of globalization it is impossible to completely cut off the country from the world economy, so other countries, primarily its main European partners, also suffer from pressure on Russia (Chuchulina et al., 2019). At the present stage, Russia is still in the transition stage to move towards an innovative model of the economy and a new technological structure (Gorda and Vitkovskaya, 2017).

Observing the Romania's situation - it is still in the transition stage after moving to EU in 2007 for releasing an innovative model of the economy and a new technological structure, which results in a gradual diversification of commodity exports by increasing the share of goods with higher added value and moving away from the raw material structure of exports (Gorda and Vitkovskaya, 2017). In our article, we proceed from the following hypothesis: that the transition to European Union should have had an accelerating effect on the development of the Romanian economy and its healthcare system indicators, affecting the indicators of the development of the world economy, including the indicators of the top countries (Drew and Sriskandarajah, 2009). 


\section{Methodology}

Study is focused on general scientific methods of analysis and synthesis, methodological methods of comparative analysis, ranking and grouping, and the evolution of national health system organizational structures is studied with the aid of comparative historical methods. When analyzing the processes of foreign trade development, general scientific analysis tools, data synthesis and intellectual analysis, and statistical analysis methods were used (Zyukin et al., 2017). Content analysis methods, information and analytical materials of Russian and Romanian analytical materials and statistical data of the Federal State Statistics Service, a database for the countries of

PICBE | 198 the International Organization for Economic Development and Cooperation (FSSS, 2020), Bloomberg L.P. statistics service (Bloomberg, 2019), World Health Organisation (WHO, 2020), World Data Atlas (Numbeo, 2020), United Nations (United Nations, 2020), Global Health Security Index (GHS Index, 2019) and National Institute of Statistics in Romania (INSSE, 2019).

\section{Results and discussions}

\section{Q1. What are the current coordinates on healthcare in the world?}

To determine the effectiveness of healthcare systems in the world, Bloomberg L.P. each 2 years compiles a special rating where the effectiveness of the healthcare system according to this rating is determined on the basis of three main indicators: average life expectancy at birth, government spending on healthcare as a percentage of GDP per capita, and the cost of medical services in terms of per capita (Table 1).

Table 1. Ranking the countries by healthcare system efficiency in the world

\begin{tabular}{cccccccc} 
Country & Rating & Effect. & Life Dur. & \% GDP & \$ US, ml & Effectiveness & Effectiveness \\
Hong-Kong & 1 & $87.3(-1.6)$ & 84.3 & 5.7 & 2,222 & $88.9(+11.4)$ & 77.5 \\
Singapore & 2 & $85.6(+1.3)$ & 82.1 & 4.3 & 2,280 & $84.2(+5,6)$ & 78.6 \\
Spain & 3 & $69.3(-2.9)$ & 82.8 & 9.2 & 2,354 & $72.2(+14.1)$ & 58.1 \\
Italy & 4 & $67.6(+0.0)$ & 82.5 & 9.0 & 2,700 & $67.7(-8.6)$ & 76.3 \\
South Korea & 5 & $67.4(-4.1)$ & 82.0 & 7.4 & 2,013 & $71.5(+4.1)$ & 67.4 \\
Israel & 6 & $67.0(+0.2)$ & 82.0 & 7.4 & 2,756 & $66.8(+3.4)$ & 65.4 \\
Japan & 7 & $64.3(-3.9)$ & 83.8 & 10.9 & 3,733 & $68.2(+0.1)$ & 68.1 \\
Australia & 8 & $62.0(+0.0)$ & 82.4 & 9.4 & 4,934 & $62.0(-3.9)$ & 65.9 \\
Taiwan & 9 & $60.8(+1.1)$ & 79.1 & 6.2 & 1,401 & $59.7(0.0)$ & N/A \\
UAE & 10 & $59.1(-5.2)$ & 77.1 & 3.5 & 1,402 & $64.3(-12.7)$ & 77.0 \\
Norway & 11 & $58.9(+4.9)$ & 82.3 & 10.0 & 7,464 & $54.0(-9.0)$ & 63.0 \\
Switzerland & 12 & $58.4(+0.6)$ & 82.9 & 12.1 & 9,818 & $57.8(-0.1)$ & 57.9 \\
Ireland & 13 & $58.2(0.0)$ & 81.5 & 7.8 & 4,757 & N/A (0.0) & N/A \\
Greece & 14 & $56.0(-3.0)$ & 81.0 & 8.4 & 1,505 & $59.0(-21.6)$ & 80.6 \\
New Zealand & 15 & $55.6(0.0)$ & 81.5 & 9.3 & 3,554 & N/A (0.0) & N/A \\
Canada & 16 & $55.5(-0.6)$ & 82.1 & 10.4 & 4,506 & $56.1(+3.2)$ & 52.9 \\
France & 17 & $55.5(-0.6)$ & 82.3 & 11.1 & 4,026 & $56.1(-8.5)$ & 64.6 \\
Portugal & 18 & $55.4(+5.9)$ & 81.1 & 9.0 & 1,722 & $49.6(+2.4)$ & 47.2 \\
\hline Romania & $\mathbf{3 7}$ & $\mathbf{4 6 . 0}(-1.2)$ & $\mathbf{7 5 . 0}$ & $\mathbf{5 . 0}$ & $\mathbf{0 , 4 4 2}$ & $\mathbf{4 7 . 2 ( + 0 . 4 )}$ & $\mathbf{4 6 . 8}$ \\
Russia & $\mathbf{5 3}$ & $\mathbf{3 1 . 3}(+\mathbf{+ 7 . 0})$ & $\mathbf{7 1 . 2}$ & $\mathbf{5 . 6}$ & $\mathbf{0 , 5 2 4}$ & $\mathbf{2 4 . 3}(+\mathbf{1 . 8})$ & $\mathbf{2 2 . 5}$ \\
\hline
\end{tabular}

Source: Compiled by the authors based on the data (Bloomberg, 2019)

Russia and Romania are 53 and 37 respectively of the rating, but still in the 55 list. So, in 2014, the last place in the rating was occupied by Russia, which was included for the first time, gaining only 24.3 points. Russia was included only in 2014 , because before that it had an average 
life expectancy in the country much lower than the required one. Russia with an efficiency rating of 31.3 which itself increased at 7.0 in comparison to 2016 and thereby remained to be in the 55 list. Romania is in the last thirteen, along with such countries as Serbia, Bulgaria, etc. However, compared to the 2016 estimate, Romania fell by 3 points in 2018, and the efficiency itself decreased by 1.2 points.

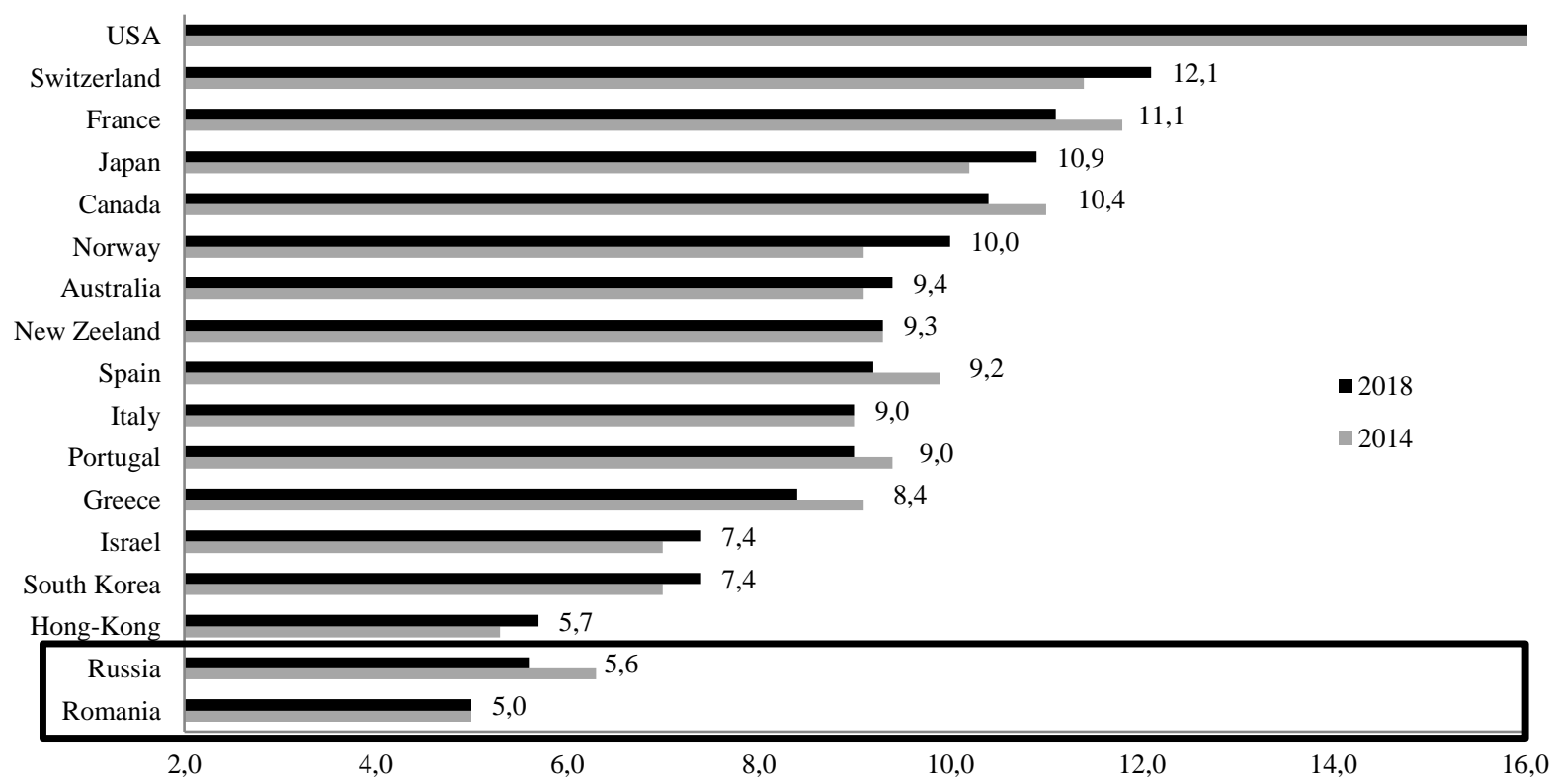

Figure 1. Total health expenditure in countries in 2018 and 2014, as \% of GDP

Source: Compiled by the authors based on the data (Bloomberg, 2019).

The largest amount of healthcare spending (Figure 1) is observed in the following countries as the United States, Norway and Switzerland. Russia and Romania are outsiders below $30^{\text {th }}$ ratings along with such countries as Bulgaria, Belarus, Serbia, etc. In Russia expenditures on healthcare are 5.6\% of GDP in 2018. In Romania this percentage equals 5,0\% of GDP in 2018.

Service "Numbeo" has published statistics where information is collected on the basis of a survey of residents of the respective countries. General indicator was compiled - the index of the quality of the healthcare system, which comprehensively reflects how bad or good everything is in the country with medicine (Figure 2).

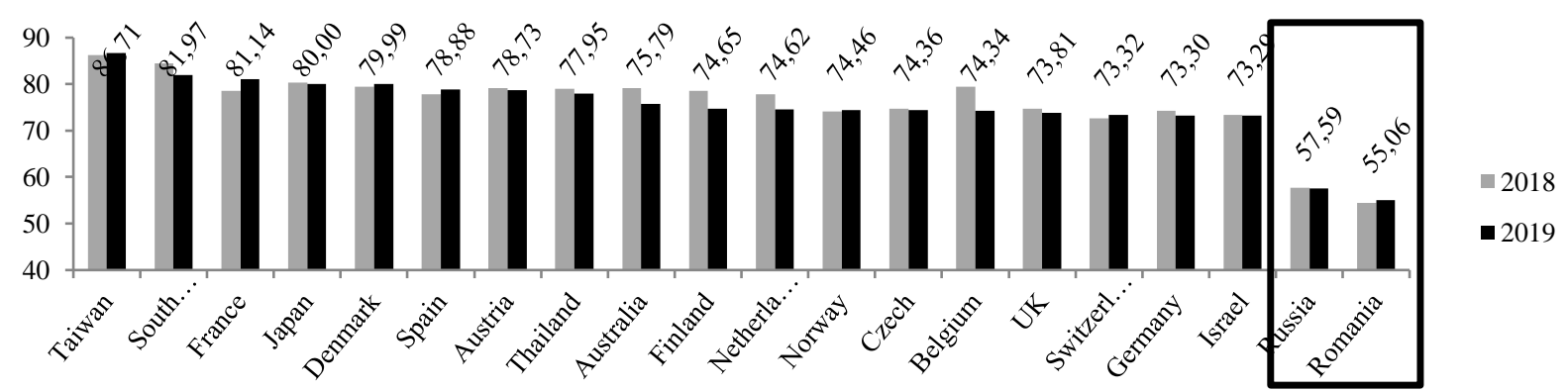

Figure 2. Healthcare index for country in 2018 and 2014, in \%

Source: Compiled by the authors based on the data (Numbeo, 2020). 
Russia and Romania are outsiders under $30^{\text {th }}$ position. Here Russia got just 57,59\% for the overall quality of the healthcare service. Romania got 55,06\% for healthcare index, which means a rather low position on the above-mentioned signs of the healthcare system. The Global Health Security Index is an international health survey that evaluates the effectiveness of healthcare systems in all countries of the world. The current version of the ranking of countries on the level of health safety was published in 2019 (Figure 3).

PICBE |

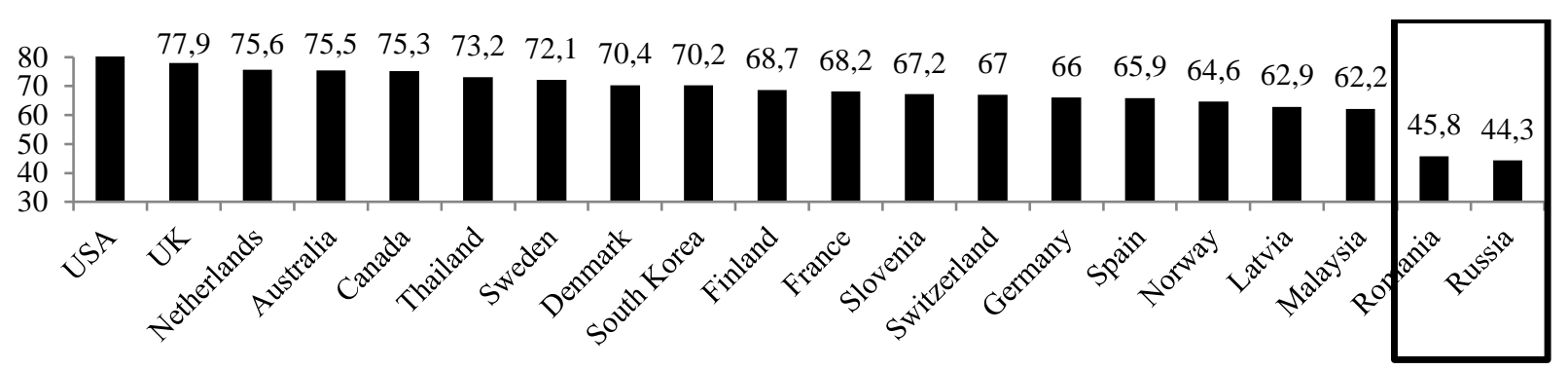

Figure 3. The Global Health Security Index for Country in 2019, in \%

Source: Compiled by the authors based on the data (GHS Index, 2019).

Top three are the USA $(83,5 \%)$, UK $(77,9 \%)$ and the Netherlands $(75,6 \%)$. Russia $(44,3 \%)$ and Romania $(45,8 \%)$ were included in the group of countries with a poor average level of medical training. In Russia, the worst indicators were epidemiology workforce, risk communication, political and security risks. In Romania, the worst indicators were emergency preparedness and response planning, financing. At the same time, Russia's biosecurity, real-time reporting, response times and infrastructure adequacy are high. In Romania all the prevention areas, real-time reporting, response operation and healthcare access with international commitments. We analyzed main indicators of health performance (Table 2).

Table 2. Key indicators of health financing and its performance in 2019

\begin{tabular}{|cccc} 
Country & \multicolumn{3}{c}{ Health performance indicators (per 1,000 people) } \\
Birth Rate & Mortality & Life Expectancy \\
South Korea & 8.3 & 6 & 83.5 \\
Taiwan & 8.2 & 8 & 81.0 \\
Australia & 12 & 6 & 83.9 \\
UK & 12 & 9 & 81.8 \\
Spain & 9 & 9 & 84.0 \\
Japan & 7.5 & 11 & 85.0 \\
France & 12.1 & 9 & 83.1 \\
Norway & 12.2 & 8 & 82.9 \\
Switzerland & 10.5 & 8 & 84.2 \\
Canada & 10.2 & 8 & 82.9 \\
Singapore & 8.7 & 5 & 84.1 \\
Portugal & 8.2 & 11 & 82.6 \\
New Zealand & 13.1 & 7 & 82.8 \\
Italy & 8.5 & 11 & 84.0 \\
USA & 12.4 & 9 & 79.1 \\
Israel & 17.9 & 5 & 83.5 \\
Hong-Kong & 8.8 & 6 & 85.3 \\
Greece & 8.3 & 11 & 82.8 \\
\hline Romania & $\mathbf{8 . 7}$ & $\mathbf{1 4}$ & $\mathbf{7 6 . 5}$ \\
Russia & $\mathbf{1 0 . 7}$ & $\mathbf{1 2}$ & $\mathbf{7 2 . 9}$ \\
\hline
\end{tabular}

Source: Compiled by the authors based on the data (United Nations, 2020).

DOI: 10.2478/picbe-2021-0019, pp. 196-209, ISSN 2558-9652 |

Proceedings of the $15^{\text {th }}$ International Conference on Business Excellence 2021 
Russia and Romania are outsiders in case of mortality and life expectancy. Here Romania has a mortality rate of 14 people in 2019 and the average life expectancy is 76.5 years. Russia has a mortality rate of 12 people in 2019 and the average life expectancy is 72.9 years. After all the revised information, we combined all the considered healthcare indicators for each country by the place in each list of revised sources, as a result of which they are allocated, gathered and sorted for the 2019 year (Table 3).

PICBE |

201

Table 3. Average Place in considered ratings for each Country in 2019

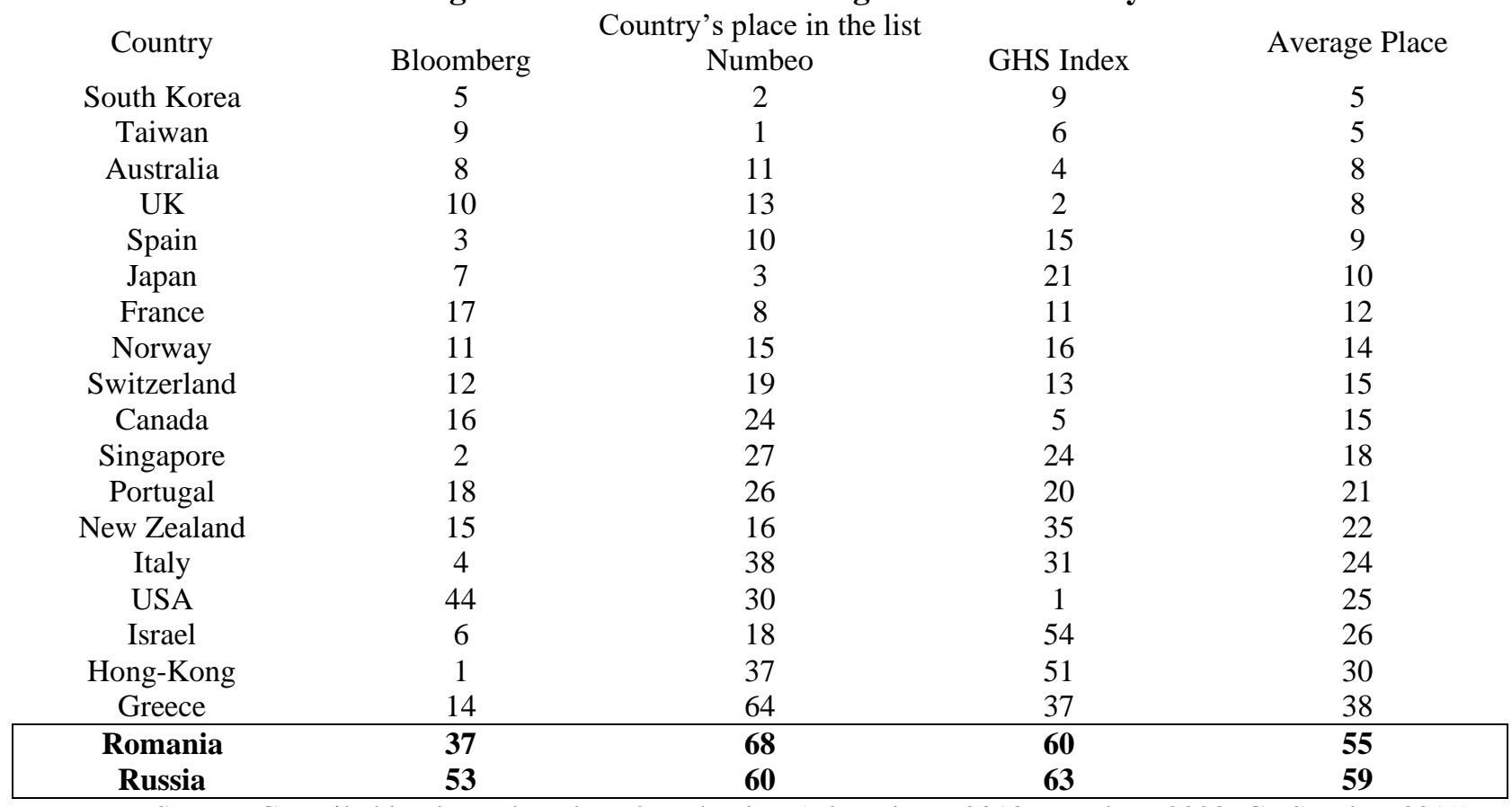

Source: Compiled by the authors based on the data (Bloomberg, 2018; Numbeo, 2020; GHS Index, 2019).

For this kind of measurement, we took results from 3 different famous ranking companies in healthcare and calculated the arithmetic mean to achieve all-in-one results. Arithmetic mean (average place) is a type of average value. In this rating Observed countries Russia and Romania are outsiders taking 59 and 55 average places respectively in the 2019 year. Outsider countries in this rating need an overall improvement in healthcare.

\section{Q2. Comparison of Russia and Romania healthcare systems}

During the formation of the healthcare system in Russia in the 2010s it went down to the values of the early 00s. But in Romania during the formation of the healthcare system, unlike Russia there wasn't a continuous increase in the number of medical personnel, while the number of doctors peaked in 2008, right after transition to the European Union, slightly decreased in future periods (Figures 4, 5). 


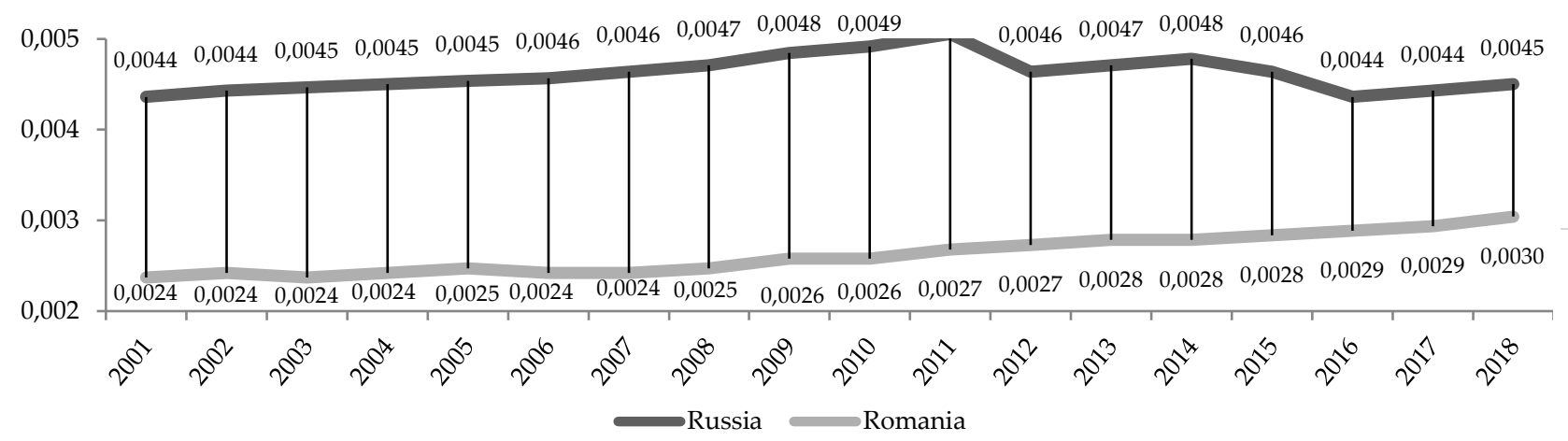

PICBE |

Figure 4. Number of first medical personnel in Russia and Romania, per capita

Source: Compiled by the authors based on the data (FSSS, 2019; INSSE, 2019).

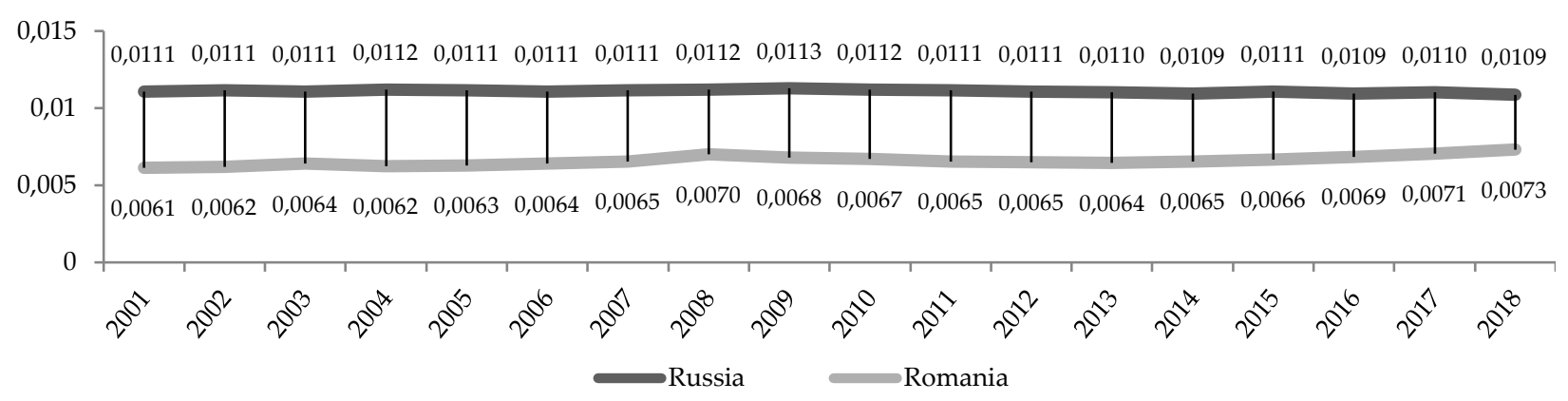

Figure 5. Number of secondary medical personnel in Russia and Romania, per capita

Source: Compiled by the authors based on the data (FSSS, 2019; INSSE, 2019).

Slight negative trends appeared in the field of emergency medical care in Russia, so until 2001 there was an increase in emergency medical care stations. At the same time, in the period from 2001 to 2005, the dynamics stabilized, and since 2005 there has been a decrease until 2019. In this context, it is also advisable to assess the equipment and enlargement of ambulance stations in this period. However, the volume of emergency medical services is also falling, although at a slower rate than the number of emergency medical stations. But indeed, negative trends appeared in the field of emergency medical care in Romania, so until 2006 there was an increase in emergency medical care stations. At the same time, in the period from 2006 to 2008, the dynamics stabilized, and since 2009 there has been a decrease until 2018, which is the same trend as in Russia (Figure 6). This could be described as more expensive equipment. In this context, it is also advisable to assess the equipment and enlargement of ambulance stations in this period. However, the volume of emergency assisted medical services is also falling, although at a slower rate than the number of emergency stations, same in Russia (Figure 7):

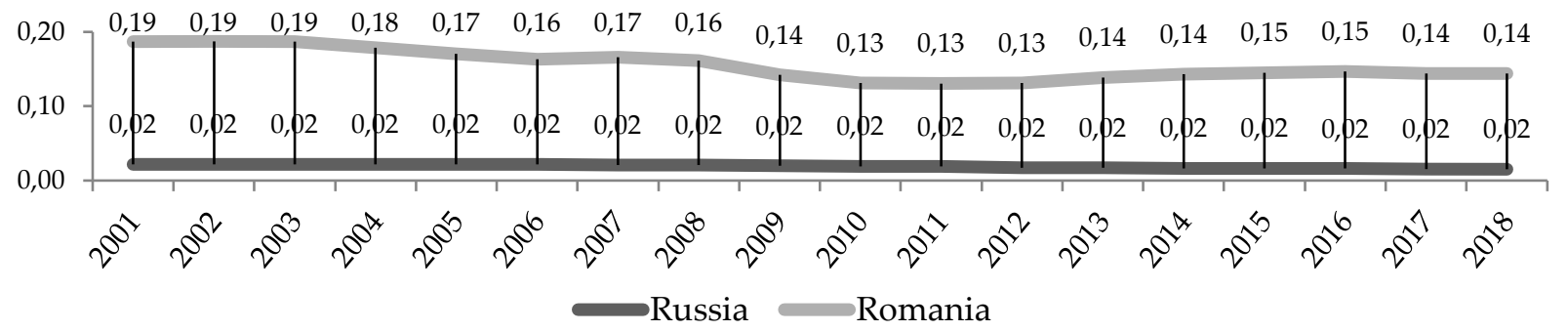

Figure 6. Number of emergency medical care stations in Russia and Romania, per 1000 people Source: Compiled by the authors based on the data (FSSS, 2019; INSSE, 2019).

DOI: 10.2478/picbe-2021-0019, pp. 196-209, ISSN 2558-9652 |

Proceedings of the $15^{\text {th }}$ International Conference on Business Excellence 2021 


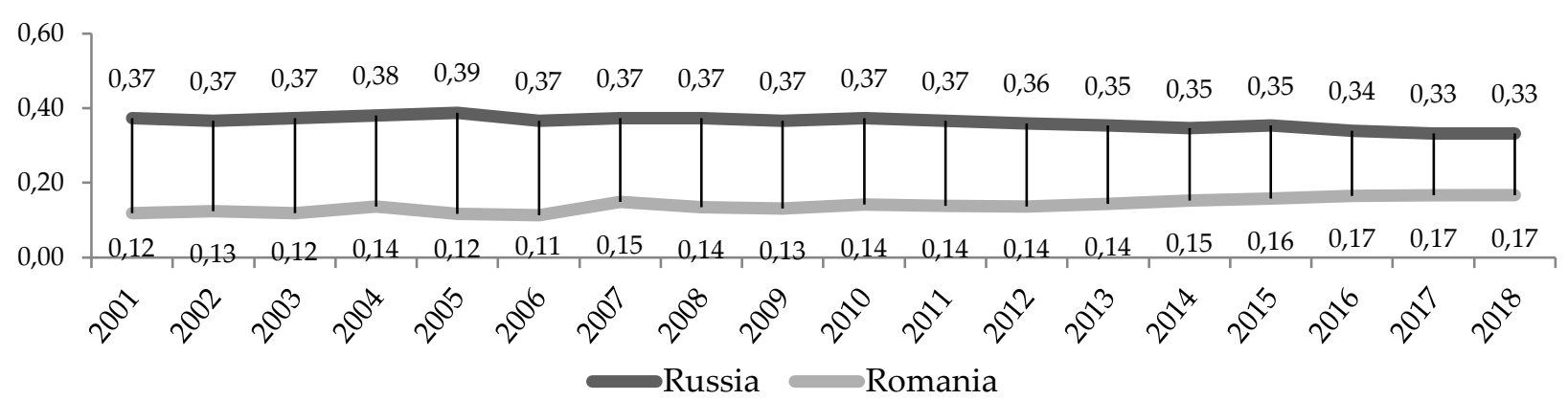

PICBE |

Figure 7. People who received outpatient and emergency care in Russia and Romania, per capita Source: Compiled by the authors based on the data (FSSS, 2019; INSSE, 2019).

It is also worth noting that as a key trend in the period from 2005 to 2019 is the reduction in the number of hospital organizations in Russia, while in Romania it's growing quite good. This trend is due to the reform of medical organizations during this period (Figure 8).

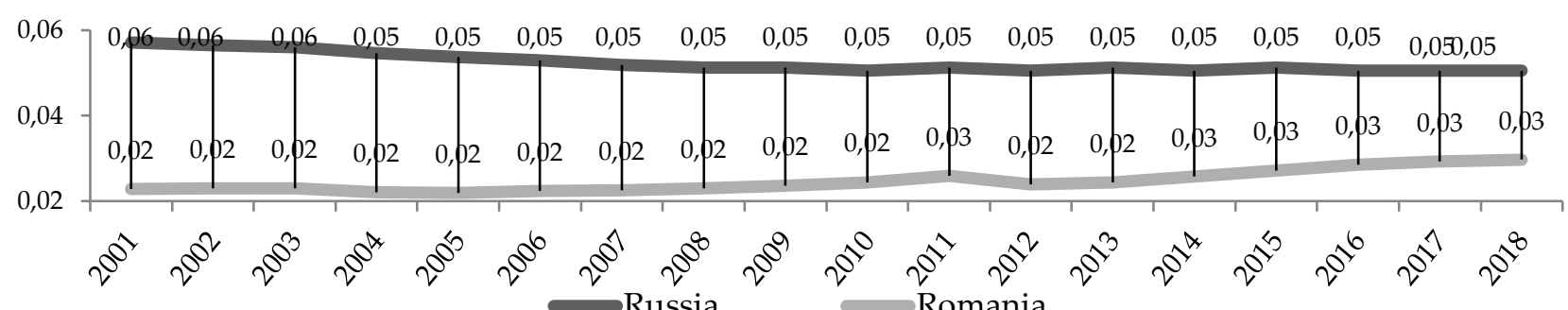

Figure 8. Number of hospitals in Russia and Romania, per 1000 people

Source: Compiled by the authors based on the data (FSSS, 2019; INSSE, 2019).

The change in the number of hospital beds (bed stock) also does not speak in favor of recent years, since the peak values for the number of hospital beds fell in 2001, gradually decreasing by 2018 (which is also due to the reduction in the number of hospital organizations in this period), same in Romania (Figure 9).

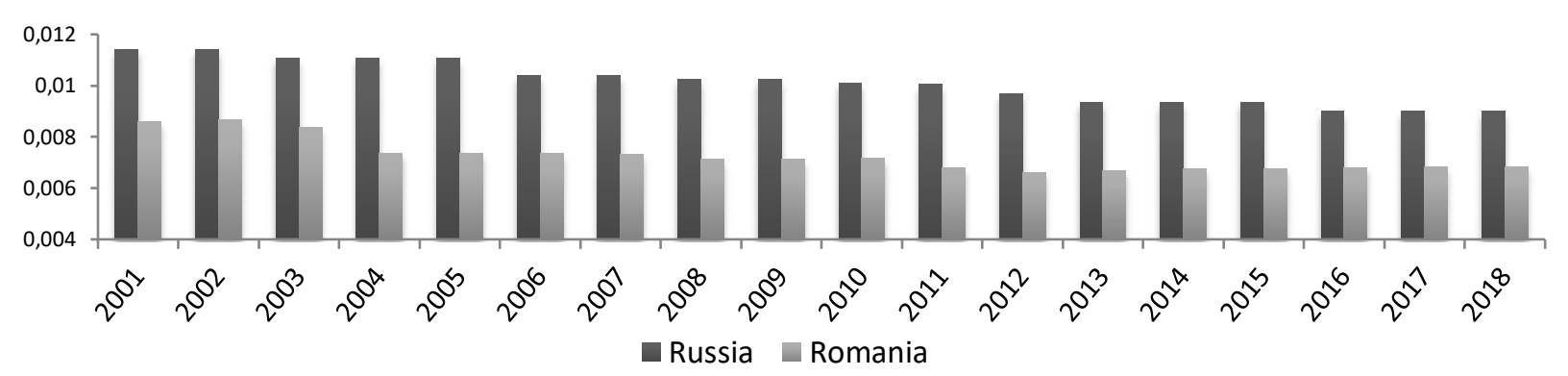

Figure 9. Number of hospital beds in Russia and Romania, million beds per capita

Source: Compiled by the authors based on the data (FSSS, 2019; INSSE, 2019).

\section{Q3. Coordinates of healthcare system in Russia}

In our article, we proceed from the following hypothesis: that sanctions for Russia in 2014 should have had a retarding effect on the development of the Russian economy and its healthcare indicators, affecting the indicators of the development of the world economy, including the indicators of the top countries. 
Paid services in the healthcare system are currently developing very actively due to the transition to the state-regulated market of medical services in the 90s, which also determines the development and institutional consolidation of the public-private healthcare management system in Russia, in million dollars \$ (Figure 10):

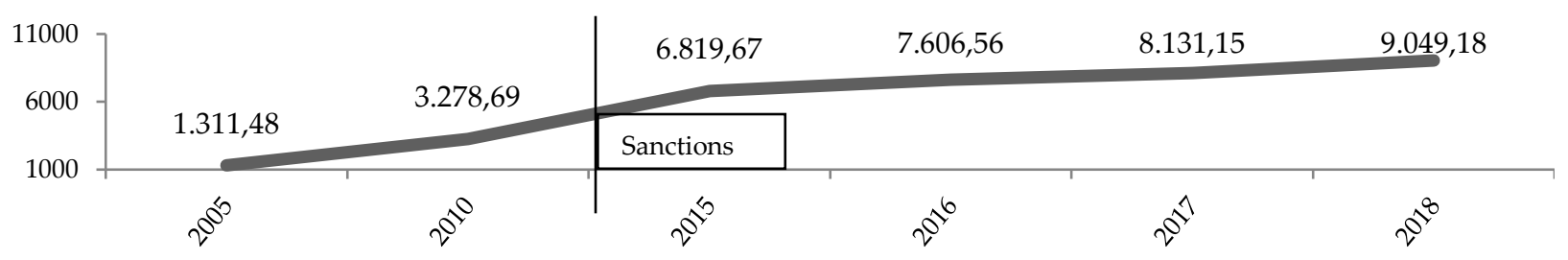

PICBE |

Figure 10. Paid services in the healthcare in Russia in 2005-2018, million (US \$) dollars

Source: Compiled by the authors based on the data (FSSS, 2019).

We will consider the qualitative characteristics of the healthcare system, and evaluate it by two indicators: disability and morbidity. In terms of disability indicators, there was a decrease in the period from 2006 to 2019, but in terms of disability (3 groups), there was an increase in 20062015. and stabilization at high rates by 2019 , which indicates such factors as the specifics of the organization of the VTEC work in terms of assigning disability, or a high level of detection of serious diseases at an early stage (Figure 11):

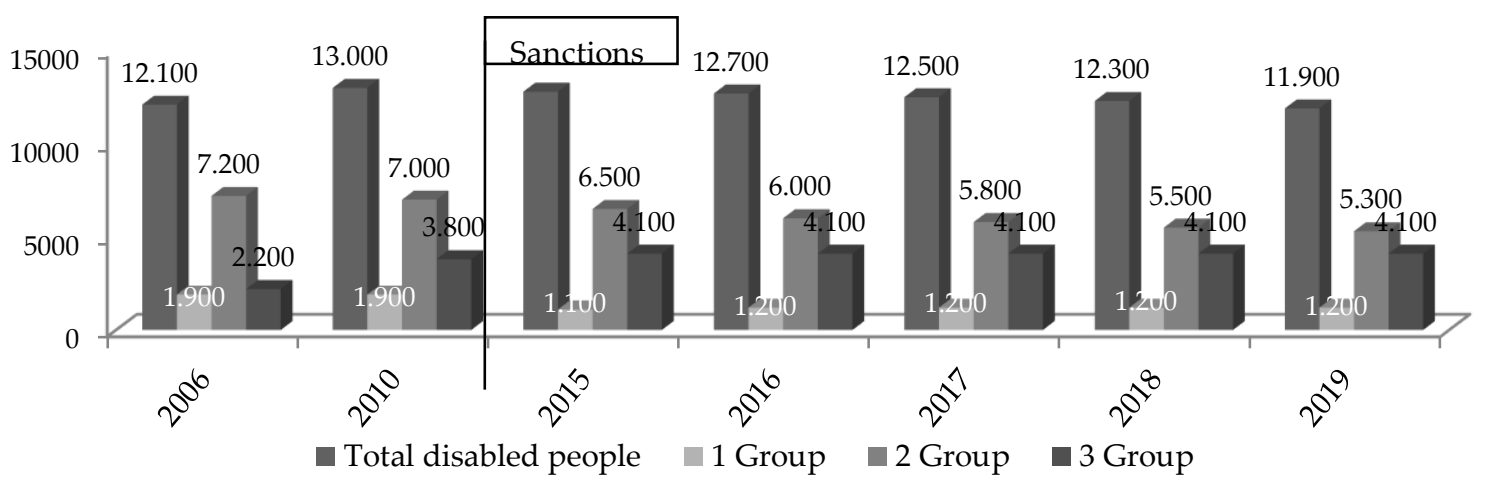

Figure 11. Disability in Russia in the years 2006-2019

Source: Compiled by the authors based on the data (FSSS, 2019).

In terms of morbidity, the situation is somewhat more negative, since there is a positive trend in comparison with 2010 for all types of diseases, which characterizes the existing healthcare system as a system with increasing problems. The growing problems in the healthcare system, quantitatively expressed in increased morbidity, apparently, is connected with the peculiarities of the sectoral data management processes and perceived weaknesses of this branch of management that can be caused by many factors. The structure of morbidity for individual diseases is presented (Figure 12). According to this structure, we also see negative scenarios for circulatory and respiratory diseases, with a general decrease in parasitic and infectious diseases. 


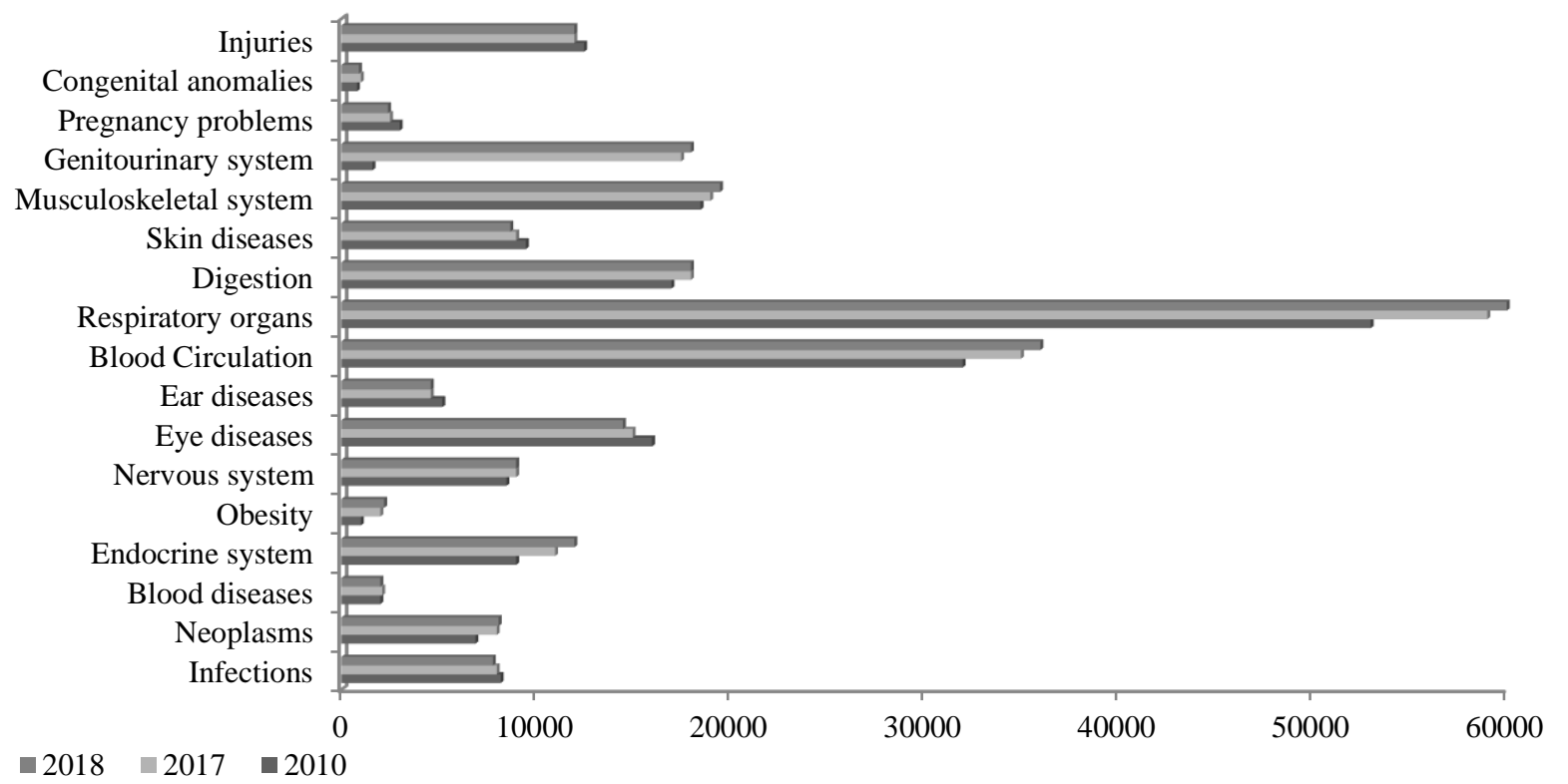

PICBE |

205

Figure 12. Dynamics and structure of morbidity by individual diseases in Russia in 2010-2018

Source: Compiled by the authors based on the data (FSSS, 2019).

We believe it is important that targeted prevention and treatment, that is, measures of support and increased funding should be in the most narrow places - i.e., the increase in the number of specialized clinics that provide specifically sectoral governance issues: for example, the growing number of diseases of blood circulation.

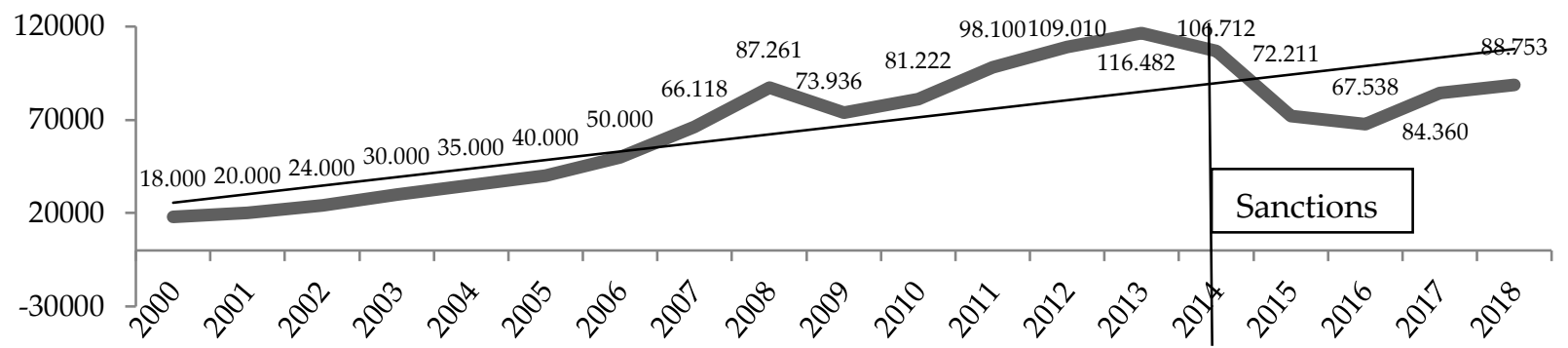

Figure 13. Current expenditure on healthcare in Russia from 2000 to 2018, thousand (US \$) dollars

Source: Compiled by the authors based on the data (FSSS, 2019).

There is a significant increase in expenditures on healthcare till 2008, it can be described as the loss of import substitution of medical equipment. In 2014 there was a significant decrease in expenditures which can be described as the Russian crisis due to US sanctions in relation to Russia. In 2016 most of the sanctions were cancelled, so the graph is growing slightly.

Concluding the section, the development of the modern healthcare system in Russia can be assessed as not very positive, since with the overall reduction in the number of medical personnel and the number of medical institutions in the 90s, this trend line continues at the moment, although in a more smoothed form. Commonplace in the healthcare system development is the rise of paid medical services and the industry orientation of the state authorities towards the development of the market of medical services to the population with the strengthening of the role of the private sector. The healthcare system is undergoing, on the one hand, an upswing due to the growth of 
investment caused by coronavirus infection, and, on the other hand, especially for "traditional" diseases, the trend outlined in previous years continues.

\section{Q4. Coordinates of healthcare system in Romania}

We will consider the qualitative characteristics of the healthcare system, and evaluate it by two indicators: disability and morbidity. In terms of disability indicators, there was an increase in the period from 2008 to 2010, which can be obviously seen after the transition to the EU, many people started to receive certificates for more privileges from the government. But right after that period from to 2013 to 2017 the number of issued certificates is lying on the ground, which indicates the concern of the population in relation to the price of the treatment with the new legislation after 2007 (Figure 14):

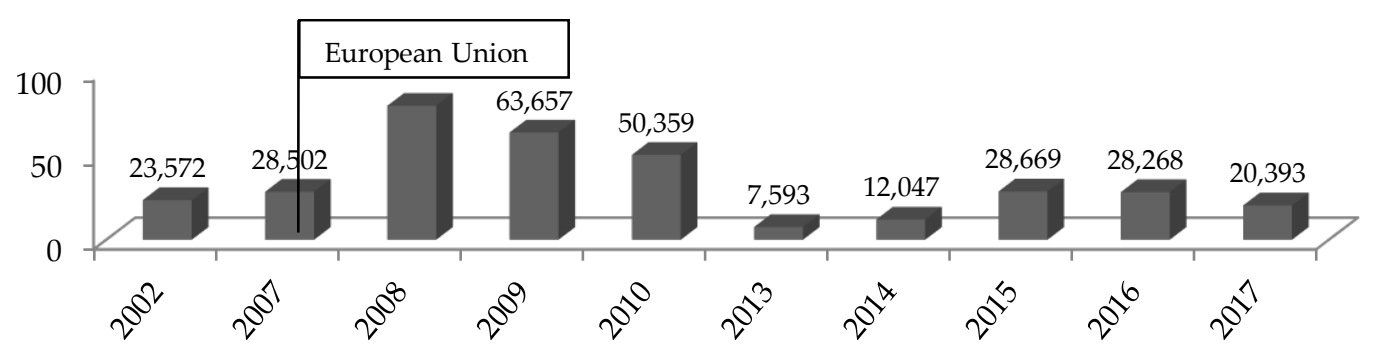

Figure 14. Issued disability certificates in Romania in 2002-2017

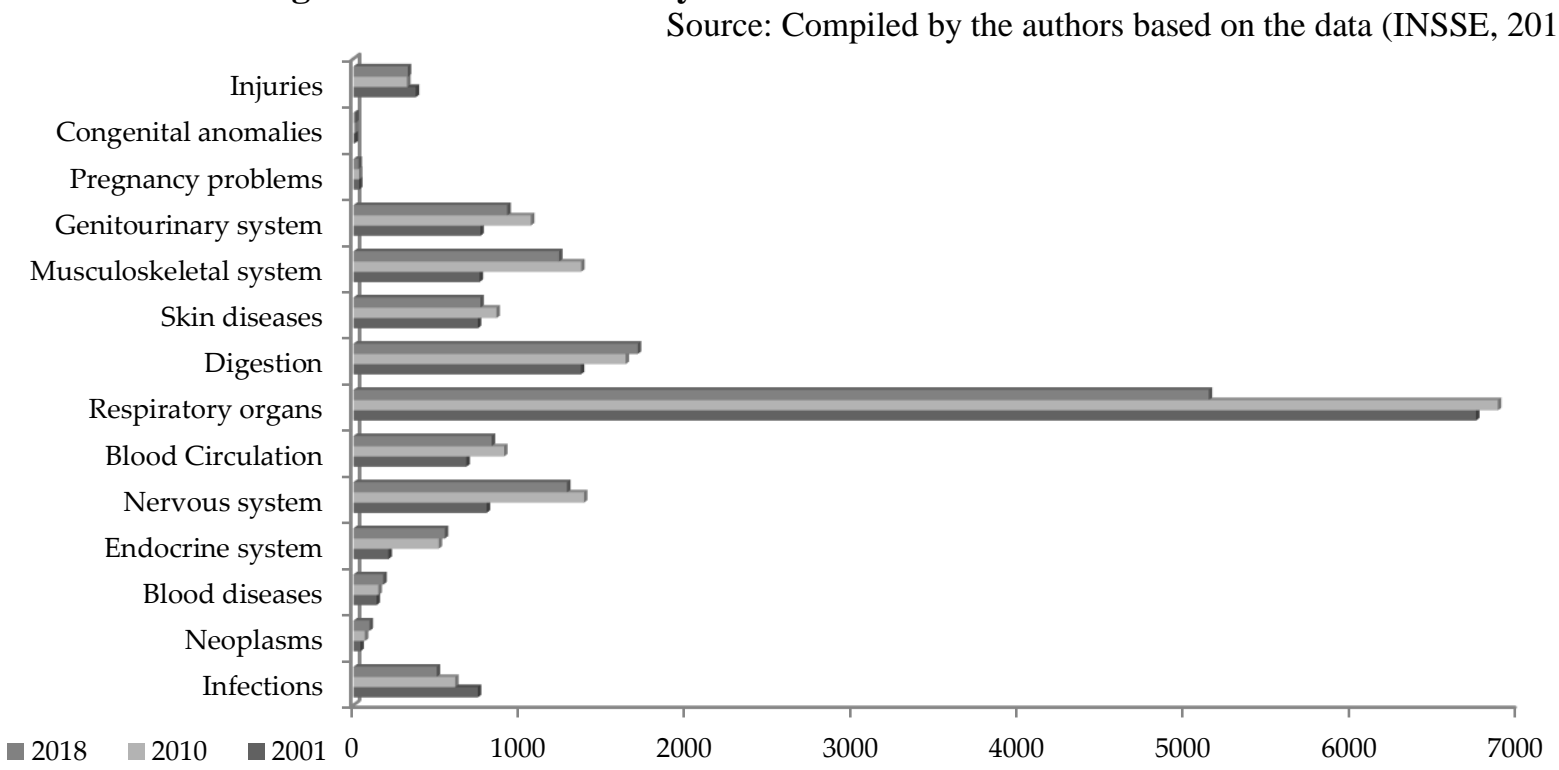

Figure 15. Dynamics and structure of morbidity by individual diseases in Romania

Source: Compiled by the authors based on the data (INSSE, 2019).

In terms of morbidity (Figure 15), the situation is somewhat negative in relation to 2001, but since there is a positive trend in comparison to 2010 for nearly all common types of diseases, then it characterizes that the existing healthcare is a system with no obvious problems. But still, the growing problems in the healthcare system in last decades, quantitatively expressed in increased morbidity, apparently, is connected with the peculiarities of the sectoral data management processes and perceived weaknesses of this branch of management that can be caused by many factors internal and external environment in the healthcare system, same in Russia. There are 
negative scenarios for only respiratory diseases, with a general decrease in genitourinary system, nervous and infectious diseases. We believe it is important that targeted prevention and treatment, measures of support and increased funding should be in the narrowest places.

To conclude the main results, we need to explore total expenditure in Romania on the healthcare system from 2007 to 2018, in million (US \$) dollars (Figure 16).

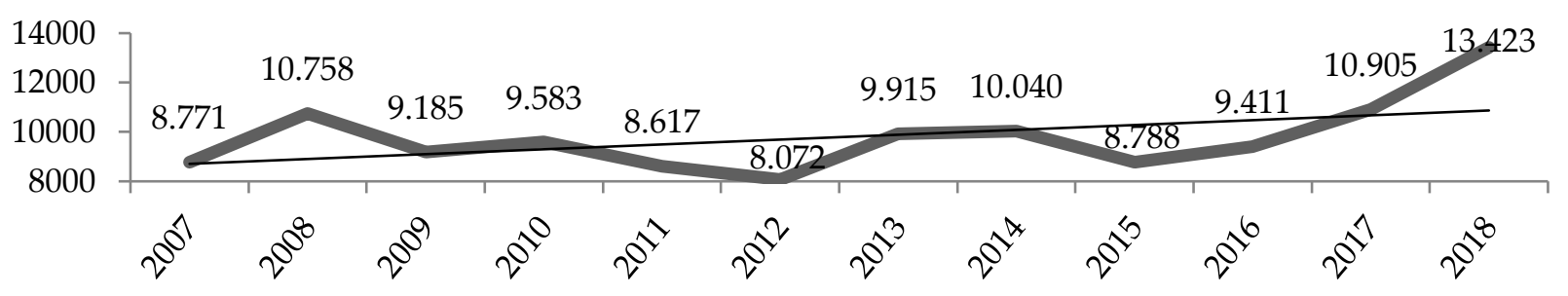

Figure 16. Current expenditure on healthcare in Romania from 2000 to 2018, thousand dollars \$ Source: Compiled by the authors based on the data (INSSE, 2019).

There is no significant increase in expenditures on healthcare during 2007 and 2017, only in 2018 it increased for more than 20\%. In 2012 and 2015 there were slight decreases in expenditures on healthcare. The situation during 2016-2018 was almost excellent, as in Russia. Thereby the main trend line tends to grow anyway.

Concluding the section, the development of the modern healthcare system in Romania can be assessed as not very positive, since with the overall reduction in the number of medical personnel and the number of medical institutions in 2000s, this trend line continues at the moment, although in a more smoothed form.

\section{Conclusion}

The results of the study were an analysis of the world's healthcare systems and an assessment of their functioning efficiency. On the basis of the conducted analysis, negative and positive trends in the development of the healthcare system in Russia and Romania are identified. The ranking of the main indicators of the development of the healthcare system in Russia and Romania is carried out. Conducting this statistical analysis for Russia and Romania in healthcare system indicators and many countries around the world we came to the conclusion that many financial and economic processes in individual countries depend on the state of the largest economies, and these two countries are no exception. Global processes taking place in the global economy can contribute to the recovery from the crisis or, on the contrary, exacerbate the existing structural problems, which happened in Russia. An important factor in the destabilization of the Russian economy which reflected mostly on the healthcare system was the political and economic sanctions imposed against it (Chuchulina, 2019; Gorda and Vitkovskaya, 2017). Therefore, Russia was the most affected by the sanctions among the countries that were also affected by. Nevertheless, these are not the main reasons for the reduction of GDP by almost $20 \%$ compared to the level of 2014. In many respects, the situation in the aggravation of the crisis in Russia's economy was the result of unfavorable conditions in stagnation in the economies of the main European partners (World Health Organization, 2020). Thus, the leaders of the world economy in recent years are in a very differentiated state, and the trend of slowing economic growth is reflected in many countries, even in China. The Russian and Romanian economies, which are tied to the supply of natural resources and raw materials (Kirillov and Putintsev, 2012), is highly dependent on the overall well-being in 
world trade, so it also finds itself in the zone of influence from its main partners - China, Japan and the EU countries, whose economies have not been in the best conditions in recent years (Bloomberg, 2019). All these problems for Russia and Romania became a catalyst for a number of financial and economic problems that led to a significant decline in Russia's GDP and stagnation for Romania's GDP to a greater extent than the average in the world.

\section{References}

PICBE |

Bloomberg, L.P. (2019). Countries with the most and least effective healthcare system, Available at: https://drive.google.com/file/d/1Zt3N2HCyaZbFlC5R6rSSETgFMsJxBC_y/view?usp =sharing.

Chernenko, E.M., Lebedeva, I.S., and Lebedev, P.V. (2018). Private-public partnership in healthcare and directions of its development: Russian business, in E.M. Chernenko (Ed.), Moscow, 19(12), 3981-3998. Available at: https://drive.google.com/file/d/1eXSb3T Xqhvcgx5aLYc-SbDPO3u5uLcaR/view?usp=sharing.

Chuchulina, E.V., Belikova, A.D., Evstratov, V.P., and Suharev, V.A. (2019). Influence of Western sanctions on the current state of the Russian economy: Economics and entrepreneurship, 2(103), 551-557. Available at: https://www.elibrary.ru/item.asp?id=37238745.

Dixon-File, S., and Tomsan, K. (2012). Rational Approach to the Consumption of Medical Services: McKinsey Quarterly, 25(2012), Available at: https://drive.google.com/file/d/ 1CFoXzN6zE_SFu0J0K6Lx4Gf0EGp6CJ6q/view?usp=sharing.

Dorgan, S., Carter, K., and Leyton, D. (2011). The importance of effective hospital management: Health International, 11, Available at: https://drive.google.com/file/d/1VCiLbicFMfN fmUH6nsL2cWmivSBVgeA9/view?usp=sharing.

Drew, C., and Sriskandarajah, D. (2009). EU Enlargement in 2007: No Warm Welcome for Labor Migrants: MPI Journal, 1(1), 1-7, Available at: https://drive.google.com/file/d/1B1etF _zeN6pgu8BPgSLH97iy_QXT1N6k/view?usp=sharing.

FSSS (2020). Russian Federal State Statistic Service, Moscow. Available at: https://eng.gks.ru/.

GHS Index (2019). Global Health Security Index, Available at: https://drive.google.com/file/d/ 1IAiGyy8ya6mbI5TXiLKB-H-5p4u-iq8V/view?usp=sharing.

Gorda, O.S., and Vitkovskaya, I.V. (2017). Influence of sanctions restrictions on Russia's commodity exports: Economic research and development, 1, 212-219.

Ianole, R., Druică, E., and Cornescu, V. (2014). Health Knowledge and Health Consumption in the Romanian Society: Procedia Economics and Finance, Bucharest, 8, 388-396, Available at: https://drive.google.com/file/d/1iUi_SsCAGDVSRAhu4xTycKyEUrOhugT5/view?us $\mathrm{p}=$ sharing.

INSSE (2020). National Institute Of Statistics Of Romania, Bucharest. Available at: https://drive.google.com/file/d/1z1iz_KgGE7CZQKVT6k9sOp5-7OzvDAW1/view?usp= sharing.

Kirillov, V B., and Putintsev, I.S. (2012). The Relations Between Russia and Romania Since 1989 in the Context of Their Foreign Policy Priorities: Bulletin of MGIMO University, Moscow, 2(23), 13-23, Available at: https://drive.google.com/file/d/1UicAE9sBWzATT6sXVxj 4GuZQ07wsz0F7/view?usp=sharing.

Numbeo (2020). Ranking of countries in the world by standard of living 2021, Belgrade. Available at: https://drive.google.com/file/d/1P1FRnbESadYsWnIQbNoS0JvP86oe0EQi/view?usp $=$ sharing. 
Orlov, E.M., and Sokolova, O.N. (2010). Category of Efficiency in the Healthcare System: Fundamental Research, 4, 70-75, Available at: https://drive.google.com/file/d/1m2 WGo-lBpvf2f5xKcLNjsAPuH9ybVTC-/view?usp=sharing.

Tashbulatova, A.N., and Tashbulatov, L.R. (2018). SWOT-Analysis Of The Current State Of The Healthcare Sector, Ufa, 6(24), 58.

United Nations (2020). United Nations Service, New-York. Available at: https://www.un.org/en/

World Health Organization (2020). World Health Organization, Geneva, Available at: https://drive.google.com/file/d/1FML7FKBO21pICXGKBcf_qvtMNIDL8WcT/view?usp

PICBE | 209 =sharing.

Zyukin, D.A., Svyatova, O.V., Belyaev, S.A., and Vlasova, O.V. (2017). Application of statistical methods, Theory and Practice KSMU, Kursk, p. 164, Available at: https://drive.google .com/file/d/1ZIyFWbbfy03fykw-ofbbHNuelRjIFnG1/view?usp=sharing. 